\title{
Prevalence of non-specific chronic low-back pain and risk factors among male soldiers in Saudi Arabia
}

\author{
Mohammad Sidiq ${ }^{1,2}$, Wadha Alenazi $^{1}$, Faizan Z Kashoo ${ }^{\text {Corresp., }}{ }^{3}$, Mohammad Qasim ${ }^{1}$, Marisia Paz Lopez ${ }^{1}$, \\ Mehrunnisha Ahmad ${ }^{4}$, Suresh Mani ${ }^{5}$, Mohammad Abu Shaphe ${ }^{6}$, Omaymah Khodairi $^{7}$, Abdulqader Almutairi ${ }^{7}$, \\ Shabir Ahmad Mir ${ }^{8}$ \\ ${ }^{1}$ Department of Rehabilitation Medicine, Northern Area Armed Force Hospital, Hafer Al-Batin, Hafer, Saudi Arabia \\ 2 Faculty of Physiotherapy, Madhav University, Abu Road, Rajasthan, India \\ 3 Department of Physical Therapy and Health Rehabilitation, College of Applied Medical Sciences, Mjamaah University, Majmaah, Riyadh, Saudi Arabia \\ 4 Department of Nursing, College of Applied Medical Sciences, Majmaah University, Majmaah, Riyadh, Saudi Arabia \\ 5 Department of Physiotherapy, Lovely Professional University, Phagwara, Punjab, India \\ 6 College of Applied Medical Sciences, Physical Therapy Department, Jazan University, Jazan, Jazan, Saudi Arabia \\ 7 Department of Physiotherapy, Armed Force Rehabilitation Center, Taif, Taif, Saudi Arabia \\ 8 Department of Medical Laboratory Sciences, College of Applied Medical Sciences, Majmaah University, Majmaah, Riyadh, Saudi Arabia \\ Corresponding Author: Faizan Z Kashoo \\ Email address: f.kashoo@mu.edu.sa
}

Background: Non-specific chronic low back pain (NSCLBP) is the most common musculoskeletal disorder affecting health and work among the military population. NSCLBP is a complex disorder with several risk factors contributing to its occurrence. Therefore, the objective of our study was to estimate the prevalence and contribution of risk factors towards NSCLBP among male soldiers in Saudi Arabia. Methods: A cross-sectional study was conducted from March 2020 to January 2021 among the military personnel at Hafar AlBatin military base, Saudi Arabia. The entire population $(n=62,000)$ at the military base were invited to participate in the study. The participants were invited to participate in the study either through direct referral from in-patient and out-patient departments of the military hospital or by invitation through pamphlets, email, and advertisement across the offices and residential areas. Soldiers reporting lower back pain for at least 12 weeks were screened for inclusion criteria at the physical therapy department of the military hospital. Inclusion criteria included pain or discomfort originating from the lower back without any known spinal diseases. Participants with a systemic inflammatory disorder, trauma, neurological symptoms, and recent spinal surgery were excluded. All eligible participants were assessed for demographic variables and risk factors and complete the Rolland Morris Disability Questionnaire and WHO-Five Well-Being Index. Results: This study identified a $46.3 \%$ prevalence of pain originating from the spine with a $2.7 \%$ prevalence of NSCLBP. Spearman's rho correlation between the severity of disability due to NSCLBP was strongly associated with age $\left(r_{s}=0.834, p<0.01\right)$, quality of sleep $\left(r_{s}=0.790, p<0.01\right)$, body mass PeerJ reviewing PDF | (2021:02:57890:4:0:NEW 11 Sep 2021) 
index (BMI) $\left(r_{s}=0.617, p<0.01\right)$, smoking $\left(r_{s}=0.520, p<0.01\right)$, co-morbidity $\left(r_{s}=0.357\right.$, $p<0.01)$, but not with the level of physical activity $\left(r_{s}=0.044, p=0.07\right)$. Conclusion: There was a high prevalence of pain originating from the spine among male Saudi soldiers with a relatively low prevalence of NSCLBP. However, the prevalence of disability due to NSCLBP was strongly associated with age, sleep quality, BMI, smoking habit, and co-morbidity. 
1 Title: Prevalence of non-specific chronic low-back pain and risk factors among male soldiers in

2 Saudi Arabia.

3 Mohammad Sidiq $^{1}$, Wadha Alenazi ${ }^{1}$, Faizan Kashoo ${ }^{2}$, Mohammad Qasim $^{1}$, Marisia Lopez ${ }^{1}$,

4 Mehrunnisha $\mathrm{Ahmad}^{3}$, Suresh mani ${ }^{4}$, Mohammad shaphe ${ }^{5}$, Omymah Khodari ${ }^{6}$, Abdulqader

5 Almutari $^{6}$, ShabirMir 7 .

6

$7{ }^{1}$ Department of Rehabilitation Medicine, Northern Area Armed Forces Hospital, Hafer Al-Batin,

8 Saudi Arabia

9 2Department of Physical Therapy and Health Rehabilitation, College of Applied Medical

10 Sciences, Majmaah University, Majmaah, Riyadh, Saudi Arabia.

$11{ }^{3}$ Department of Nursing, College of Applied Medical Sciences, Majmaah University, Majmaah, 12 Riyadh, Saudi Arabia.

$13{ }^{4}$ Department of Physiotherapy, Lovely Professional University, Punjab, India.

$14{ }^{5}$ Physical Therapy Department, Jazan University, Jazan, Saudi Arabia.

$15{ }^{6}$ Armed Force Rehabilitation center, Taif, Saudi Arabia.

$16{ }^{7}$ Department of Medical Laboratory Sciences, College of Applied Medical Sciences, Majmaah

17 University, Majmaah, Riyadh, Saudi Arabia.

19 Corresponding Author:

20 Faizan kashoo ${ }^{2}$

21 King Khalid Street, Majmaah, Riyadh, 11952, Saudi Arabia

22 Email address: f.kashoo@mu.edu.sa

23

24 Abstract

25 Background: Non-specific chronic low back pain (NSCLBP) is the most common

26 musculoskeletal disorder affecting health and work among the military population. NSCLBP is a

27 complex disorder with several risk factors contributing to its occurrence. Therefore, the objective

28 of our study was to estimate the prevalence and contribution of risk factors towards NSCLBP

29 among male soldiers in Saudi Arabia.

30 Methods: A cross-sectional study was conducted from March 2020 to January 2021 among the

31 military personnel at Hafar Al-Batin military base, Saudi Arabia. The entire population

$32(n=62,000)$ at the military base were invited to participate in the study. The participants were 
33 invited to participate in the study either through direct referral from in-patient and out-patient

34 departments of the military hospital or by invitation through pamphlets, email, and advertisement

35 across the offices and residential areas. Soldiers reporting lower back pain for at least 12 weeks

36 were screened for inclusion criteria at the physical therapy department of the military hospital.

37 Inclusion criteria included pain or discomfort originating from the lower back without any

38 known spinal diseases. Participants with a systemic inflammatory disorder, trauma, neurological

39 symptoms, and recent spinal surgery were excluded. All eligible participants were assessed for

40 demographic variables and risk factors and complete the Rolland Morris Disability

41 Questionnaire and WHO-Five Well-Being Index.

42 Results: This study identified a $46.3 \%$ prevalence of pain originating from the spine with a 2.7

$43 \%$ prevalence of NSCLBP. Spearman's rho correlations between the severity of disability due to

44 NSCLBP was strongly associated with age $\left(r_{s}=0.834, p<0.01\right)$, quality of sleep $\left(r_{s}=0.790\right.$,

$45 \mathrm{p}<0.01)$, body mass index (BMI) $\left(\mathrm{r}_{\mathrm{s}}=0.617, \mathrm{p}<0.01\right)$, smoking $\left(\mathrm{r}_{\mathrm{s}}=0.520, \mathrm{p}<0.01\right)$, co-morbidity

$46\left(\mathrm{r}_{\mathrm{s}}=0.357, \mathrm{p}<0.01\right)$, but not with the level of physical activity $\left(\mathrm{r}_{\mathrm{s}}=0.044, \mathrm{p}=0.07\right)$.

47 Conclusion: There was a high prevalence of pain originating from the spine among male Saudi

48 soldiers with a relatively low prevalence of NSCLBP. However, the prevalence of disability due

49 to NSCLBP was strongly associated with age, sleep quality, BMI, smoking habit, and co-

50 morbidity.

\section{Introduction}

53 Low back pain (LBP) is one of the most recurring medical complaints that require health care

54 intervention. It is the most frequent type of musculoskeletal disorder causing significant

55 disability and job absenteeism (Alnaami et al., 2019; Cunningham et al., 2006). More than half

56 of the general population seeks medical advice for LBP at some point in their lives (Ferreira et 
57 al., 2010). The global prevalence of LBP among the general population ranges between $15 \%$ to

$5845 \%$ (Al-Arfaj et al., 2003) and incurs a high medical cost. LBP is a multi-factorial condition, 59 and the evidence does not always support a clear cause and effect relationship (Hartvigsen et al., 60 2018). Back pain without any known cause for 12 -weeks is termed non-specific chronic low 61 back pain (NSCLBP) (Rozenberg, 2008). However, there are known risk factors associated with 62 NSCLBP. These factors can be categorized into individual and environmental factors. Individual 63 factors include a sedentary level of activity, age, smoking status, obesity, psychological stress, 64 history of back pain, and pre-existing conditions (Hulla et al., 2019). The environmental factors 65 include lifting technique, physical activity required at work, standing time, and sitting duration at 66 work (Burström et al., 2015; Campbell et al., 2011; Coenen et al., 2014; Dario et al., 2015; 67 Lardon et al., 2014).

68 Military service begins with an introductory training period. The unique characteristics of 69 military training include both the intensity and duration. Since one of the main goals of the 70 training is to improve physical performance level, the volume of physical activity increases 71 linearly during military training. In Saudi Arabia, the problem of LBP is not distinct from that in 72 other parts of the globe, and the prevalence of LBP among the general population is reported to 73 be $18.8 \%$ (Aldera et al., 2020). Specific spinal postures and physical activities have been 74 associated with LBP (Swain et al., 2020; Johanning, 2000). Soldiers are mainly at risk of 75 developing LBP due to their high physical demands of their profession. Active military 76 personnel usually carry heavy equipment during training which can lead to over-stressing of their 77 musculoskeletal system, especially the spine (Parreira et al., 2018).

78 Several risk factors have been reported to be associated with non-specific low back pain among 79 the general public (Sribastav et al., 2018). Research is scarce about the risk factors associated 
80 with NSCLBP. Only one case-control study was conducted in Iran among 92 military personnel

81 to explore the association between risk factors and the incidence of NSCLBP. Authors of the

82 study reported exercises, smoking, body mass index (BMI), education level and bad posture are

83 the potential risk factors associated with NSCLBP (Ramezani et al., 2015). Therefore,

84 identifying the other additional risk factors such as quality of sleep, age, co-morbidity towards

85 the occurrence of NSCLBP in the military population may give us a better insight into its

86 prevention strategies and treatment.

87 NSCLBP can be effectively managed with patient education, postural correction, and manual

88 therapy (Stochkendahl et al., 2018). Conversely, untreated NSCLBP may lead to poor prognosis

89 and disability (Nieminen et al., 2021). The medical cost involved in the management of

90 NSCLBP is relatively lower than the more severe form of LBP such as, radiculopathies and

91 intervertebral disc prolapsed (Bachmann et al., 2009). Therefore, identifying and treating

92 NSCLBP as soon as possible to onset would significantly reduce medical costs and absenteeism

93 from work (Miyamoto et al., 2019).

94 There are regional studies that have investigated the prevalence of LBP across Saudi Arabia 95 among health care workers. For example, in Riyadh province of Saudi Arabia, 83.9\% of medical 96 practitioners suffered from LBP (Almalki et al., 2016). The prevalence of LBP among medical 97 workers in the eastern region of Saudi Arabia was 79\% (Al Bahrani et al., 2015), and 73.9\% of 98 health care workers reported suffering from LBP in the southwest region of Saudi Arabia 99 (Alnaami et al., 2019). It was reported that $23.9 \%$ of rehabilitation professionals seek medical 100 leave due to LBP (Abolfotouh et al., 2021). There is no research literature available about the 101 prevalence of NSCLBP among general public or military soldiers in Saudi Arabia. Military 102 personnel are at a greater risk of developing LBP due to the nature of their occupation. 
103 Moreover, dietary habits, genetic make-up, culture, and routine physical activity among Saudi

104 soldiers differ from other military across the globe. Therefore, the study aimed to identify the

105 LBP, specifically NSCLBP, and the unique contribution of risk factors towards the occurrence of

106 NSCLBP among Saudi military personnel. The purpose of this cross-sectional study was to

107 estimate the prevalence and risk factors for NSCLBP among soldiers in the Saudi armed forces.

108 Materials \& Methods

109 Study design, participants and research setting

110 This cross-sectional study was conducted among the entire military population $(n=62,000)$ at

111 Hafar Al-Baten, Saudi Arabia, from March 2020 to January 2021. The military base comprises

112 administrative buildings, sports complexes, training grounds, residential areas, and general

113 hospitals.

114 King Fahd Medical City (KFMC) Institutional Review Board approved the study (IRB 19-033E).

115 Hafar Al-baten military base only recruits male soldiers; therefore only male soldiers were

116 enrolled in this study using a purposive sampling method. Participants were invited to participate

117 in the study through pamphlets, emails, and advertisements across the offices and residential

118 areas or referred to physical therapy department from in-patient or out-patient departments of the

119 military hospital. All participants who were under military training or in-service were eligible to

120 participate in this study. Soldiers reporting with LBP were screened for inclusion criteria.

121 Inclusion criteria included pain or discomfort originating from the lumbosacral region without

122 any known cause, which lasted for at least 12 weeks, without any radiating or specific spinal

123 diseases. The persistence of NSCLBP for 12 weeks is considered chronic (Hallegraeff et al.,

124 2012). Participants who were currently suffering from NSCLBP were eligible to participate in

125 the study. The informed consent form was signed by each participant, with the complete

126 information provided about the study procedures. Four physical therapists at the physical therapy 
127 department at King Khalid military hospital (Hafar Batin) carried out physical examinations 128 based on a recommended clinical guideline to diagnose NSCLBP (Oliveira et al., 2018). A 129 review of medical records, identification of red flags, and radiographic imaging were conducted 130 to identify the systemic cause of LBP. The physical examination was divided into seven sections 131 that included observation (posture and gait), a functional activity that reproduced symptoms, 132 active movement of the lumbar spine and hip, palpation of the lumbar spine and sacral region, 133 assessment of core muscle such as transverse abdominis, multifidus, and pelvic control, a 134 neurological examination which includes myotome, dermatome, sensation, straight leg raise test 135 and femoral nerve test and last was pain related work issues and conflicts (McCarthy et al., 136 2006). Participants with a prolapsed inter-vertebral disk, back surgery, or vertebral column 137 disorders were excluded from the study. However, participants with systemic disorders such as 138 hypertension or diabetes mellitus not related to the cause of backache were included in the study 139 (Figure 1).

140 The primary outcome of the study was the prevalence of NSCLBP among military personnel in

141 Saudi Arabia. Assuming a 95\% confidence level, with an expected prevalence between 53.2\% to $14279.17 \%$ LBP based upon an earlier study (Awaji, 2016) with 0.05 absolute precision, the 143 required sample size was between 255 to 382 military personnel. However, the questionnaire 144 was distributed to the military population at the military base comprising 620000 military 145 personnel. A total of 28706 responded with back pain with a $46.3 \%$ response rate.

\section{Instrumentation}

147 Participants who met the inclusion criteria and signed the consent form were eligible to 148 participate in the study, with the complete information provided about the study procedures.

149 Participants were examined for demographic data such as age, weight, height, years of service 
150 and interviewed for role in the military and history of smoking, and medical records were

151 reviewed for any pre-existing conditions. BMI was classified according to the WHO

152 classification as underweight (less than $18.5 \mathrm{~kg} / \mathrm{m} 2)$, normal $(18.5-24.9 \mathrm{~kg} / \mathrm{m} 2)$, overweight

153 (25.0-29.9 kg/m2), and obese (30.0 kg/m2 and above) (Purnell, 2018). Participants were also

154 categorized into age groups as 20-30, 31-40, and 41-50 years. Each participant had to self-report

155 the Arabic version of Rolland Morris Disability Questionnaire (RMDQ), the Arabic version of

156 Pittsburgh quality of sleep, WHO-Five Well-being Index (WHO-5), and level of physical

157 activity. The severity of disability due to back pain among participants was evaluated by a cross-

158 culturally translated and validated Arabic version of RMDQ (Maki et al., 2014). Based on the

159 RMDQ scoring, participants were characterized as mild, moderate, or severe disabilities. The

160 Arabic version of the RMDQ has a high internal consistency (Cronbach $\alpha=0.72$ ) and reliability

$161(\mathrm{ICC}=0.900 ; 95 \% \mathrm{CI}=0.753-0.951)$ and good agreement $(\mathrm{ICC}=0.925, \mathrm{CI}=0.81-0.97)$ with the

162 English version of RMDQ (Maki et al., 2014).

163 The quality of sleep among participants was evaluated by an Arabic validated version of PSQI

164 (Suleiman et al., 2010). In scoring the PSQI, seven component scores are derived, each scored 0

165 (no difficulty) to 3 (severe difficulty). The component scores are summed to produce a global

166 score (range 0 to 21). A global score of 5 or more indicates poor sleep quality; the higher the

167 score, the worse the quality. The Arabic version of PSQI is reported to have good reliability,

168 (Cronbach $\alpha=0.77$ ) acceptable internal consistency, (Cronbach $\alpha=0.65)$ and moderate to a high

169 correlation between global PSQI and five components of PSQI scores (Al Maqbali et al., 2020;

170 Suleiman et al., 2010).

171 Quality of life was evaluated by the Arabic version of the WHO-5 (Sibai et al., 2009).

172 Participants reported their quality of life status by marking on a 5-point rating scale for five 
173 statements. The score was multiplied by 4 to obtain the $0-100$ range. Zero stands for the worst

174 possible quality of life, while 100 stands for the best possible quality of life. The Arabic version

175 of the WHO-5 showed good internal consistency and test-retest reliability (Cronbach $\alpha=0.88$ /

$176 r=0.73)($ Sibai et al., 2009)

177 Physical activity level was categorized into four levels based on the number of military drills

178 performed by the participants per week. Sedentary physical activity meant that the individual

179 was not involved in military drills; light meant that the individual performed military drills once

180 or twice a week; moderate implied thrice or four times a week, and vigorous implied five to all

181 days of a week.

182 Statistical procedures

183 Data were collected in Microsoft excel (2007) and analyzed by IBM SPSS (version 20). The 184 ordinal scale data such as level of physical activity, BMI, WHO-5, and RMDQ were analyzed 185 using Spearman rank-order analysis. Ordinal regression analysis was conducted between age, 186 years in service, smoking, military rank, quality of sleep, level of physical activity, BMI, and 187 WHO-5, with RMDQ as the independent variable. Descriptive statistics were performed to 188 generate frequency and percentage for each variable.

\section{Results}

190 Out of 62000 contacted for the survey, $28706(46.3 \%)$ responded with pain originating from the 191 spine and 1678 (2.7\%) with NSCLBP (figure 2). The mean age of military personnel with 192 NSCLBP was $32.5 \pm 7.41$ years and a mean BMI of $25.74 \pm 3.10 \mathrm{~kg} / \mathrm{m} 2$. Out of 1678 193 participants, $617(74.5 \%)$ had mild, 679 (40.5\%) moderate, or $382(22.8 \%)$ severe intensities of 194 NSCLBP. 
195 The younger age group (20-30 years) reported mild $(\mathrm{n}=617,87.3 \%)$ to moderate $(\mathrm{n}=90,12.7 \%)$

196 back pain disability as compared to the older age group. A total of $228(13.5 \%)$ participants in

197 this study were obese, out of which 93 (40.8\%) reported severe disability due to NSCLBP.

198 Participants engaging in a vigorous level of physical activity reported mild back pain disability $199(n=222,13.2 \%)$ compared to sedentary participants $(n=206,65.2 \%)$. The NSCLBP prevalence 200 was highest among corporal ranked military officers $(n=396,23.5 \%)$ than others. Further 201 analysis revealed that corporal ranked officers were overweight $(n=216,54.5 \%)$ and engaged in a 202 moderate level of activity $(n=182,45.9 \%)$. Out of 404 active smokers, the majority (91.8\%) 203 reported mild back pain disability (Table 1).

204 Four hundred and four (48\%) of participants reported a co-morbidity such as diabetes $(\mathrm{n}=141$, $2058.4 \%)$, hypertension $(n=21,1.3 \%)$, respiratory conditions $(n=175,10.4 \%)$, arthritis $(n=9,0.5 \%)$, 206 neck pain $(n=97,5.8 \%)$, and shoulder pain $(n=364,21.7 \%)$.

207 There was a strong positive correlation between RMDQ with days lost due to back pain, $208\left(\mathrm{r}_{\mathrm{s}}(1678)=.902, \mathrm{p}=.001\right)$, RMDQ with age $\left(\mathrm{r}_{\mathrm{s}}(1678)=.834, \mathrm{p}=.001\right)$, RMDQ with years in 209 service $\left(\mathrm{r}_{\mathrm{s}}(1678)=.828, \mathrm{p}=.001\right)$, RMDQ with BMI $\left(\mathrm{r}_{\mathrm{s}}(1678)=.617, \mathrm{p}=.001\right)$, RMDQ with 210 cigarette smoking $\left(\mathrm{r}_{\mathrm{s}}(1678)=.520, \mathrm{p}=.001\right)$, RMDQ with quality of sleep $\left(\mathrm{r}_{\mathrm{s}}(1678)=.566, \mathrm{p}=\right.$ $211.001)$, and a strong negative correlation between RMDQ with well-being $\left(\mathrm{r}_{\mathrm{s}}(1678)=-.740, \mathrm{p}=\right.$ $212.001)$, and RMDQ with working hours $\left(\mathrm{r}_{\mathrm{s}}(1678)=-.681, \mathrm{p}=.001\right)$. Details of the other 213 significant correlations between variables are given in Table 2.

214 An ordinal regression analysis was conducted to predict relationships between dependent 215 (RMDQ scores) and independent variables (BMI, age, smoking status, level of activity). An 216 increase in BMI was associated with an increase in the odds of higher scores in the RMDQ, with 217 an odds ratio of $0.106(95 \% \mathrm{CI}, 0.023$ to 0.189$)$, Wald $\chi^{2}(1)=6.270, \mathrm{p}=0.012$. An increase in 
218 age (expressed in years) was associated with an increase in the odds of higher scores in the

219 RMDQ, with an odds ratio of 0.494 (95\% CI, 1.196 to 1.357 ), Wald $\chi 2(1)=95.792, \mathrm{p}<001$.

220 Participants who did not smoke cigarettes were -1.350 (95\% CI, -2.143 to -1.013$)$ times less

221 likely to score higher on RMDQ than smokers, with a statistically significant effect, Wald $\chi^{2}$ (1)

$222=8.964, \mathrm{p}=.003$. Military personal engaging in severe military drills were -1.578 times $(95 \%$

223 CI, 1.196 to 1.357$)$ Wald $\chi^{2}(1)=6.270, p=0.012$, less likely to score higher on the RMDQ than 224 personnel engaging in sedentary and light military drills.

\section{Discussion}

226 The prevalence of back pain among military personnel was $46.3 \%$, which included pain 227 originating from the lumbosacral region $(54.6 \%)$, thorax region $(21.5 \%)$, and cervical region 228 (17.8\%). The prevalence of NSCLBP was 2.7\% among the population of 62000 armed forces. 229 The low prevalence of NSCLBP in this study may be due to stringent inclusion criteria. Such as, 230 participants eligible were currently suffering from NSCLBP, pain arising from lumbo-sacral 231 region only and no history of known cause or trauma. A study conducted by Chan et al. among 232 Malaysian military personnel $(n=330)$ reported a prevalence of $48.9 \%$ of LBP. However, LBP 233 was assessed through a questionnaire (Nordic Musculoskeletal Questionnaire) without 234 identifying the type and region of pain. The study also included female participants $(\mathrm{n}=27,8 \%)$ 235 and LBP was associated with smoking, history of LBP, history of the accident, lifting weight, 236 and job-related activities (Chan et al., 2019). Another study conducted by Monnier et al. in 2015 237 among $(\mathrm{n}=272)$ Swedish armed force marines reported $19.9 \%$ and $36.0 \%$ musculoskeletal pain 238 originating from the thoracic and lumbar region of vertebral column, respectively. The present 239 study included $97 \%$ of male marine soldiers (Monnier et al., 2015). A study conducted by Vun et 240 al. in 2018 among navy, army, and air force military personnel $(n=6696)$ in Canada reported a 
241 significant association between the mental health of armed forces and the intensity of back pain.

242 The present study included male $(n=5773)$ and female $(n=923)$ participants and reported $23 \%$ of

243 chronic pain arising from the lumbar region of the spine (Vun et al., 2018). A study conducted by

244 Cardoso et al. in 2018 in Brazil reported a back pain prevalence of 58.8\% among military police

245 battalion, affecting their daily living activities. However, participants ( $\mathrm{n}=97)$ with scoliosis,

246 anterior head; lumbar and cervical hyperlordosis; thoracic hyperkinesis, and decreased spinal

247 curvatures were included. The study classified disability due to back pain based on scores

248 obtained from the Oswestry Disability Index (Cardoso et al., 2018). A study by Hou et al. in

2492013 reported that the prevalence of LBP among Chinese $(n=1642)$ soldiers were highest among

250 armored forces $(51.3 \%)$ than in the artillery $(27.5 \%)$ or infantry $(11.9 \%)$. Authors of the present

251 study also reported that the prevalence was higher among participants involved in night training,

252 cross-country race, and grenade-throwing. There was no formal assessment conducted for back

253 pain. Participants in the study were merely asked to recall if they had back pain in the previous

254 two months (Hou et al., 2013).

255 A study conducted by Ernat et al. in 2012 among active infantry soldiers in the USA reporting

256 acute back pain noted that the soldiers seldom seek medical care as they think that the back pain

257 is a normal part of their occupation. The low prevalence of NSCLBP in our study might be due

258 to a similar perception among Saudi male soldiers. However, future research is needed to explore

259 the perception of Saudi military about LBP. Authors of the present study also reported the

260 incidence of LBP about 39.9 per 1000 person-years among all infantrymen. However, the data

261 were extracted from the physician's retrospective medical records of military personnel (Ernat et

262 al., 2012). 
263 The percentage of participants who reported smoking in our study was $24.7 \%(n=404)$. Smoking 264 was moderately correlated to the number of days lost due to back pain, higher scores on the back 265 pain disability questionnaire, higher BMI, and lower wellbeing index. About 371, 91.8\% of 266 active cigarette smokers out of 404 belonged to the age group of 20-30 years and were suffering 267 from mild to moderate back pain disability. These results were supported by a meta-analysis of 268 cross-sectional studies revealing a strong association between smoking and the prevalence of low 269 back pain (Shiri et al., 2010). Authors of the present study also reported that incidence of LBP 270 was more substantial in adolescents than in adults. Therefore, an early counseling session to quit 271 smoking at an early age would improve the overall health of younger military recruits (Pirie et 272 al., 2013).

273 Physical fitness is of paramount importance among people undergoing or seeking military 274 training. Military personnel complete strenuous physical training to meet the demanding role in 275 various positions. Our study found a significant variation in the level of physical activity 276 performed at different ranks in the military. We found that the level of physical activity was 277 negatively correlated with the age group. Participants engaging in mild to moderate physical 278 activity reported statistically significant improvement in their quality of life (WHO-5) compared 279 to sedentary level class. It was also noted that participants engaging in a vigorous level of 280 physical activity only experience a mild form of disability due to LBP. The level of physical 281 activity among participants was limited due to the COVID-19 pandemic. It could be the possible 282 reason behind a lack of significance between activity level and amount of back pain disability.

283 In our study, participants in the age group of $41-50$ years reported $66 \%$ severe disability due to 284 back pain compared to younger age groups. In contrast, research conducted among US veterans 
$285(n=67,696)$ reported that young male veterans $(18-39$ years $)$ were 3.1 times more likely to report 286 severe pain than the older age group (Nahin, 2017).

287 We found that poor quality of sleep among participants reporting moderate to severe back pain 288 disability. Similarly, research conducted in US military hospitals among 757 participants 289 reported that sleep disorder is significantly associated with LBP-related health visits among the 290 military population (Rhon et al., 2019). In addition, a cohort study conducted among adults 291 reported improvement in LBP with increased sleep quality (Kovacs et al., 2018). However, there 292 is a lack of research articles regarding the quantity and quality of sleep required to recover from 293 strenuous military drills.

294 There were no significant differences in the severity of back pain disability due to the role 295 performed in the military. However, a higher number of Corporals reported mild back pain 296 disability when compared to other ranked officers. The sedentary administrative level of activity 297 performed at the military offices by the corporal-ranked officers could be the possible reason 298 behind the high prevalence of NSCLBP.

299 The quality of life assessed by WHO-5 showed that participants reporting mild back pain 300 disability were at minimal risk, and those with severe back pain disability were at substantial risk 301 of developing poor health-related quality of life.

\section{Limitations}

303 There are many limitations to this cross-sectional study. There is a bias involved in self-reported 304 questionnaires. However, validated Arabic-translated questionnaires were used to overcome the 305 language barrier. The type of military-specific activities was not evaluated for each participant. 306 The Novel Coronavirus pandemic during the study period may have affected the reported level 307 of activity among participants. The inclusion of only male soldiers in our study limits 
308 transferability to other militaries. Moreover, the physiological characteristic such as frequency of

309 previous episodes, intensity of pain and remission period was not assessed among participants.

310 The data were obtained from one military base in Saudi Arabia, therefore limiting the

311 generalization to the entire military population in Saudi Arabia. However, the Hafar batin

312 military city in Saudi Arabia is the largest military base in Saudi Arabia.

\section{Conclusions}

314 Our study reports a high prevalence of pain disability originating from the spine (46.8\%) among 315 military personnel in Saudi Arabia with a $2.7 \%$ prevalence of NSCLBP. Strong associations 316 were found between back pain disability and age group, role in military, smoking, BMI, level of 317 activity, pre-existing conditions, quality of sleep, and WHO-5 among military personnel. The 318 data can be used to develop risk management strategies such as smoking cessation programs at 319 the military base to reduce the prevalence of NSCLBP. The research data can be utilized to 320 update the health care policy for early rehabilitation of military personnel exhibiting signs and 321 symptoms of NSCLBP. The research data can be used to conduct future research on association 322 between risk factors and NSCLBP among military population globally.

\section{Acknowledgments}

324 We would like to thank the Academic and training department of Northern Area Armed Forces

325 Hospital, especially the research unit, for supporting and encourage us through the research 326 process.

327

328

329

330

331

332

333

334

\section{References}

Abolfotouh, M., Alomair, F., Alangari, D., Bushnak, I., Aldebasi, B., \& Almansoof, A. (2021). Epidemiology of work-related lower back pain among rehabilitation professionals in Saudi Arabia. Eastern Mediterranean Health Journal, 27(4), 390-398.

Al-Arfaj, A. S., Al-Saleh, S. S., Alballa, S. R., Al-Dalaan, A. N., Bahabri, S. A., Al-Sekeit, M. A., \& Mousa, M. A. (2003). How common is back pain in Al-Qaseem region. Saudi Medical Journal, 24(2), 170-173. 
335

336

337

338

339

340

341

342

343

344

345

346

347

348

349

350

351

352

353

354

355

356

357

358

359

360

361

362

363

364

365

366

367

368

369

370

371

372

373

374

375

376

377

378

379

380

Al Bahrani, A., Al Huwaykim, M., Al Kuwaiti, A., Alalwi, M., Al Dulaim, H., \& Al Mazeedi, T. (2015). Prevalence of Low Back Pain in Healthcare Workers in Eastern Region in Saudi Arabia. Int J Sci Res, 6.

Al Maqbali, M., Hughes, C., Gracey, J., Rankin, J., Dunwoody, L., \& Hacker, E. (2020). Validation of the Pittsburgh Sleep Quality Index (PSQI) with Arabic cancer patients. Sleep and Biological Rhythms, 18, 217-223.

Aldera, M. A., Alexander, C. M., \& McGregor, A. H. (2020). Prevalence and Incidence of Low Back Pain in the Kingdom of Saudi Arabia: A Systematic Review. Journal of Epidemiology and Global Health, 0. https://doi.org/10.2991/jegh.k.200417.001

Almalki, M., Alkhudhayri, M. H., Batarfi, A. A., Alrumaihi, S. K., Alshehri, S. H., Aleissa, S. I., \& Alkenani, N. S. (2016). Prevalence of low back pain among medical practitioners in a tertiary care hospital in Riyadh. Saudi Journal of Sports Medicine, 16(3), 205.

Alnaami, I., Awadalla, N. J., Alkhairy, M., Alburidy, S., Alqarni, A., Algarni, A., Alshehri, R., Amrah, B., Alasmari, M., \& Mahfouz, A. A. (2019). Prevalence and factors associated with low back pain among health care workers in southwestern Saudi Arabia. BMC Musculoskeletal Disorders, 20(1), 1-7. https://doi.org/10.1186/s12891-019-2431-5

Awaji, M. A. (2016). Epidemiology of low back pain in Saudi Arabia. Journal of Advances in Medical and Pharmaceutical Sciences, 1-9.

Bachmann, S., Wieser, S., Oesch, P., Schmidhauser, S., Knüsel, O., \& Kool, J. (2009). Threeyear cost analysis of function-centred versus pain-centred inpatient rehabilitation in patients with chronic non-specific low back pain. Journal of Rehabilitation Medicine, 41(11), 919 923.

Burström, L., Nilsson, T., \& Wahlström, J. (2015). Whole-body vibration and the risk of low back pain and sciatica: a systematic review and meta-analysis. International Archives of Occupational and Environmental Health, 88(4), 403-418. https://doi.org/10.1007/s00420014-0971-4

Campbell, P., Wynne-Jones, G., \& Dunn, K. M. (2011). The influence of informal social support on risk and prognosis in spinal pain: A systematic review. European Journal of Pain, 15(5), 444.e1-444.e14. https://doi.org/10.1016/j.ejpain.2010.09.011

Cardoso, E. S., Fernandes, S. G. G., Corrêa, L. C. de A. C., Dantas, G. A. de F., \& Câmara, S. M. A. da. (2018). Low back pain and disability in military police: an epidemiological study. Fisioterapia Em Movimento, 31.

Chan, E. W. M., Hamid, M. S. A., Din, F. H. M., Ahmad, R., Nadzalan, A. M., \& Hafiz, E. (2019). Prevalence and factors associated with low back pain among Malaysian army personnel stationed in Klang Valley. Biomedical Human Kinetics, 11(1), 9-18.

Coenen, P., Gouttebarge, V., Van Der Burght, A. S. A. M., Van Dieën, J. H., Frings-Dresen, M. H. W., Van Der Beek, A. J., \& Burdorf, A. (2014). The effect of lifting during work on low back pain: A health impact assessment based on a meta-analysis. Occupational and Environmental Medicine, 71(12), 871-877. https://doi.org/10.1136/oemed-2014-102346

Cunningham, C. G., Flynn, T., \& Blake, C. (2006). Low back pain and occupation among Irish health service workers. Occupational Medicine, 56(7), 447-454. https://doi.org/10.1093/occmed/kq1056

Dario, A. B., Ferreira, M. L., Refshauge, K. M., Lima, T. S., Ordoñana, J. R., \& Ferreira, P. H. (2015). The relationship between obesity, low back pain, and lumbar disc degeneration when genetics and the environment are considered: A systematic review of twin studies. Spine Journal, 15(5), 1106-1117. https://doi.org/10.1016/j.spinee.2015.02.001

Peer] reviewing PDF | (2021:02:57890:4:0:NEW 11 Sep 2021) 
381

382

383

384

385

386

387

388

389

390

391

392

393

394

395

396

397

398

399

400

401

402

403

404

405

406

407

408

409

410

411

412

413

414

415

416

417

418

419

420

421

422

423

424

425

426

Ernat, J., Knox, J., Orchowski, J., \& Owens, B. (2012). Incidence and risk factors for acute low back pain in active duty infantry. Military Medicine, 177(11), 1348-1351.

Ferreira, M. L., Machado, G., Latimer, J., Maher, C., Ferreira, P. H., \& Smeets, R. J. (2010). Factors defining care-seeking in low back pain-a meta-analysis of population based surveys. European Journal of Pain, 14(7), 747-e1.

Hallegraeff, J. M., Krijnen, W. P., van der Schans, C. P., \& de Greef, M. H. G. (2012).

Expectations about recovery from acute non-specific low back pain predict absence from usual work due to chronic low back pain: a systematic review. Journal of Physiotherapy, 58(3), 165-172.

Hartvigsen, J., Hancock, M. J., Kongsted, A., Louw, Q., Ferreira, M. L., Genevay, S., Hoy, D., Karppinen, J., Pransky, G., Sieper, J., Smeets, R. J., Underwood, M., Buchbinder, R., Cherkin, D., Foster, N. E., Maher, C. G., van Tulder, M., Anema, J. R., Chou, R., ... Woolf, A. (2018). What low back pain is and why we need to pay attention. The Lancet, 391(10137), 2356-2367. https://doi.org/10.1016/S0140-6736(18)30480-X

Hou, Z., Shi, J., Hong, Y. E., NI, Z., Jun, Y. A. O., Zheng, L., Liu, Z., Ying, G. A. O., \& Jian, W. (2013). Prevalence of low back pain among soldiers at an army base. Chinese Medical Journal, 126(4), 679-682.

Hulla, R., Brecht, D., Stephens, J., Salas, E., Jones, C., \& Gatchel, R. (2019). The biopsychosocial approach and considerations involved in chronic pain. Healthy Aging Research, 08(01), 6-12. https://doi.org/10.35248/har.2019.8.6

Johanning, E. (2000). Evaluation and management of occupational low back disorders. American Journal of Industrial Medicine, 37(1), 94-111. https://doi.org/10.1002/(SICI)10970274(200001)37:1<94::AID-AJIM8>3.0.CO;2-X

Kovacs, F. M., Seco, J., Royuela, A., Betegon, J. N., Sánchez-Herráez, S., Meli, M., Martinez Rodriguez, M. E., Nunez, M., Álvarez-Galovich, L., \& Moyá, J. (2018). The association between sleep quality, low back pain and disability: A prospective study in routine practice. European Journal of Pain, 22(1), 114-126.

Lardon, A., Leboeuf-Yde, C., Le Scanff, C., \& Wedderkopp, N. (2014). Is puberty a risk factor for back pain in the young? A systematic critical literature review. Chiropractic and Manual Therapies, 22(1), 1-12. https://doi.org/10.1186/s12998-014-0027-6

Maki, D., Rajab, E., Watson, P. J., \& Critchley, D. J. (2014). Cross-cultural translation, adaptation, and psychometric testing of the Roland-Morris disability questionnaire into modern standard Arabic. Spine, 39(25), E1537-E1544.

McCarthy, C., Rushton, A., Billis, V., Arnall, F., \& Oldham, J. (2006). Development of a clinical examination in non-specific low back pain: a Delphi technique. Journal of Rehabilitation Medicine, 38(4), 263-267.

Miyamoto, G. C., Lin, C.-W. C., Cabral, C. M. N., van Dongen, J. M., \& van Tulder, M. W. (2019). Cost-effectiveness of exercise therapy in the treatment of non-specific neck pain and low back pain: a systematic review with meta-analysis. British Journal of Sports Medicine, 53(3), 172-181.

Monnier, A., Larsson, H., Djupsjöbacka, M., Brodin, L.-Å., \& Äng, B. O. (2015). Musculoskeletal pain and limitations in work ability in Swedish marines: a cross-sectional survey of prevalence and associated factors. BMJ Open, 5(10).

Nahin, R. L. (2017). Severe pain in veterans: The effect of age and sex, and comparisons with the general population. The Journal of Pain, 18(3), 247-254.

Nieminen, L. K., Pyysalo, L. M., \& Kankaanpää, M. J. (2021). Prognostic factors for pain

Peer] reviewing PDF | (2021:02:57890:4:0:NEW 11 Sep 2021) 
427

428

429

430

431

432

433

434

435

436

437

438

439

440

441

442

443

444

445

446

447

448

449

450

451

452

453

454

455

456

457

458

459

460

461

462

463

464

465

466

467

468

469

470

471

472

chronicity in low back pain: a systematic review. Pain Reports, 6(1).

Oliveira, C. B., Maher, C. G., Pinto, R. Z., Traeger, A. C., Lin, C.-W. C., Chenot, J.-F., van Tulder, M., \& Koes, B. W. (2018). Clinical practice guidelines for the management of nonspecific low back pain in primary care: an updated overview. European Spine Journal, 27(11), 2791-2803.

Parreira, P., Maher, C. G., Steffens, D., Hancock, M. J., \& Ferreira, M. L. (2018). Risk factors for low back pain and sciatica: an umbrella review. The Spine Journal, 18(9), 1715-1721. https://doi.org/10.1016/J.SPINEE.2018.05.018

Pirie, K., Peto, R., Reeves, G. K., Green, J., Beral, V., \& Collaborators, M. W. S. (2013). The 21st century hazards of smoking and benefits of stopping: a prospective study of one million women in the UK. The Lancet, 381(9861), 133-141.

Purnell, J. Q. (2018). Definitions, classification, and epidemiology of obesity. Endotext [Internet].

Ramezani, M., Taghizade, G., Abdolvahab, M., Lajavardi, L., \& Saeidi Brojeni, M. (2015). Investigating of risk factors related to chronic non-specific low back pain in military men. Journal of Modern Rehabilitation, 9(3), 54-63.

Rhon, D. I., O’Hagan, E., Mysliwiec, V., \& Lentz, T. A. (2019). Does Disordered Sleep Moderate the Relationship Between Pain, Disability and Downstream Health Care Utilization in Patients With Low Back Pain?: A Longitudinal Cohort From the US Military Health System. Spine, 44(21), 1481-1491.

Rozenberg, S. (2008). Chronic low back pain: definition and treatment. La Revue Du Praticien, 58(3), 265-272.

Shiri, R., Karppinen, J., Leino-Arjas, P., Solovieva, S., \& Viikari-Juntura, E. (2010). The association between smoking and low back pain: a meta-analysis. The American Journal of Medicine, 123(1), 87-e7.

Sibai, A. M., Chaaya, M., Tohme, R. A., Mahfoud, Z., \& Al-Amin, H. (2009). Validation of the Arabic version of the 5-item WHO Well Being Index in elderly population. Int $J$ Geriatr Psychiatry, 24(1), 106-107.

Sribastav, S. Sen, Long, J., He, P., He, W., Ye, F., Li, Z., Wang, J., Liu, H., Wang, H., \& Zheng, Z. (2018). Risk factors associated with pain severity in patients with non-specific low Back pain in southern China. Asian Spine Journal, 12(3), 533.

Stochkendahl, M. J., Kjaer, P., Hartvigsen, J., Kongsted, A., Aaboe, J., Andersen, M., Andersen, M. Ø., Fournier, G., Højgaard, B., \& Jensen, M. B. (2018). National Clinical Guidelines for non-surgical treatment of patients with recent onset low back pain or lumbar radiculopathy. European Spine Journal, 27(1), 60-75.

Suleiman, K. H., Yates, B. C., Berger, A. M., Pozehl, B., \& Meza, J. (2010). Translating the Pittsburgh sleep quality index into Arabic. Western Journal of Nursing Research, 32(2), 250-268.

Swain, C. T. V., Pan, F., Owen, P. J., Schmidt, H., \& Belavy, D. L. (2020). No consensus on causality of spine postures or physical exposure and low back pain: A systematic review of systematic reviews. Journal of Biomechanics, 102(2020), 109312. https://doi.org/10.1016/j.jbiomech.2019.08.006

Vun, E., Turner, S., Sareen, J., Mota, N., Afifi, T. O., \& El-Gabalawy, R. (2018). Prevalence of comorbid chronic pain and mental health conditions in Canadian Armed Forces active personnel: analysis of a cross-sectional survey. CMAJ Open, 6(4), E528.

Peer) reviewing PDF | (2021:02:57890:4:0:NEW 11 Sep 2021) 


\section{Table 1 (on next page)}

Demographic variables and grouping of variables for military personal with non-specific chronic low back pain.

n, number; \%, percentage; WHO, world Health Organization 


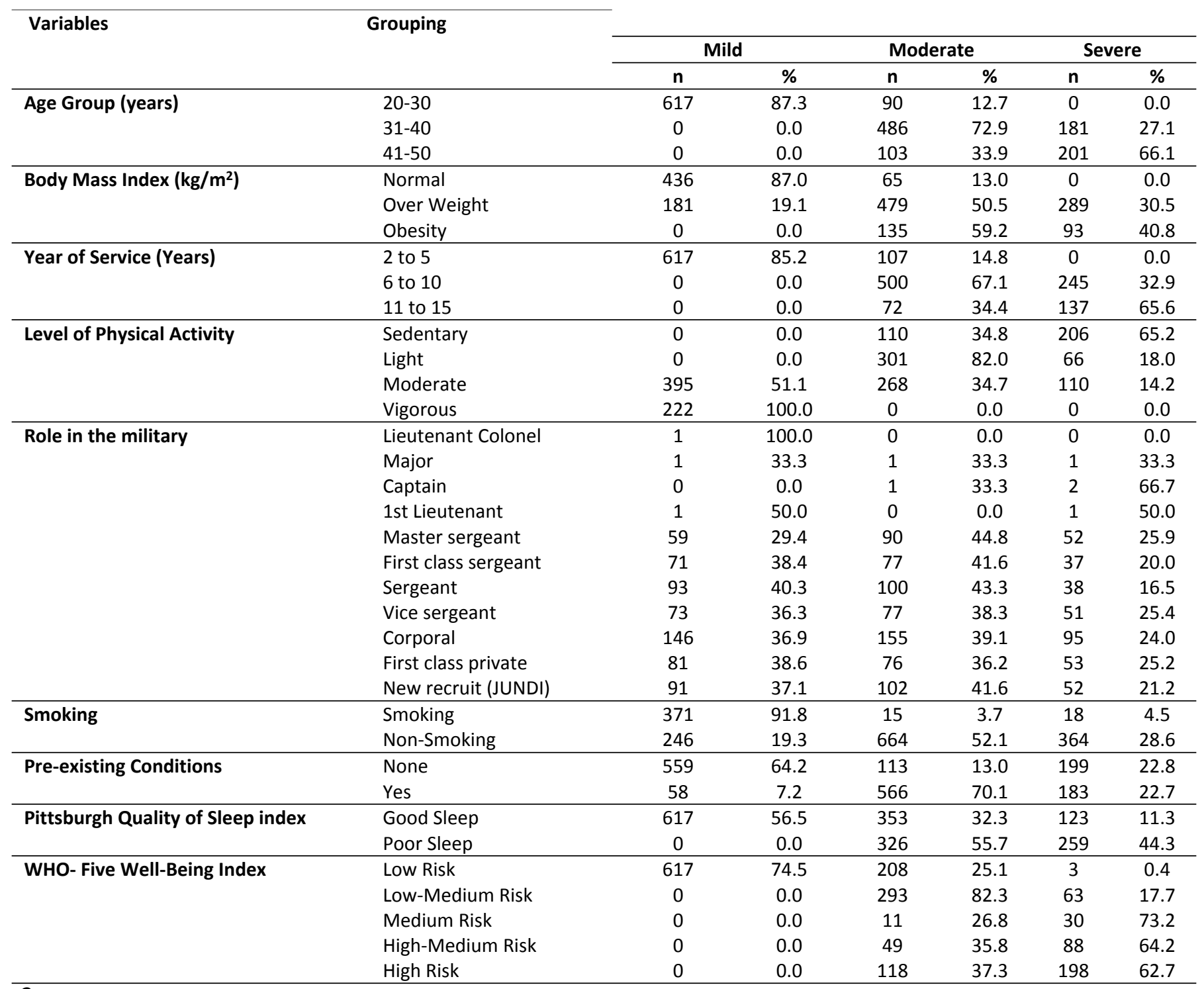

3

4

5

6

7

8

9 


\section{Table 2 (on next page)}

Correlation matrix

BMI; body mass index, RMDQ; Rolland Morris Disability Questionnaire. Spearman's rho correlation is significant at the 0.01 level (2-tailed). $\mathrm{N}=1678, * p<.05 ;{ }^{* *} p<.01$ 


\begin{tabular}{|c|c|c|c|c|c|c|c|c|c|c|c|c|}
\hline & & 1 & 2 & 3 & 4 & 5 & 6 & 7 & 8 & 9 & 10 & 11 \\
\hline 1 & $\begin{array}{l}\text { Level of physical } \\
\text { activity }\end{array}$ & & & & & & & & & & & \\
\hline 2 & Role in the military & .007 & & & & & & & & & & \\
\hline 3 & Smoking & $-.272^{* *}$ & -.023 & & & & & & & & & \\
\hline 4 & Co-morbidity & $-.547^{* *}$ & -.012 & $.514^{\star \star}$ & & & & & & & & \\
\hline 5 & $\begin{array}{l}\text { Number of days } \\
\text { lost (days) }\end{array}$ & -.044 & -.036 & $.568^{* \star}$ & $.458^{* *}$ & & & & & & & \\
\hline 6 & Age & .036 & -.022 & $.624^{* *}$ & $.385^{* *}$ & $.838^{* \star}$ & & & & & & \\
\hline 7 & Years in service & .033 & -.022 & $.612^{* *}$ & $.382^{* *}$ & $.831^{* *}$ & $.984^{* *}$ & & & & & \\
\hline 8 & BMI & $-.104^{* *}$ & -.036 & $.442^{* *}$ & $.357^{\star *}$ & $.644^{* *}$ & $.681^{* *}$ & $.688^{* *}$ & & & & \\
\hline 9 & $\begin{array}{l}\text { Well being index } 5 \\
\text { (WHO) }\end{array}$ & $-.096^{* *}$ & .009 & $-.423^{* *}$ & $-.175^{* *}$ & $-.729^{* *}$ & $-.862^{* *}$ & $-.864^{* *}$ & $-.633^{* *}$ & & & \\
\hline 10 & RMDQ & .044 & -.018 & $.520^{* *}$ & $.357^{* *}$ & $.902^{* *}$ & $.834^{* *}$ & $.828^{* *}$ & $.617^{* *}$ & $-.740^{\star *}$ & & \\
\hline 11 & $\begin{array}{l}\text { Pittsburgh Quality } \\
\text { of sleep }\end{array}$ & -.044 & $-.048^{*}$ & $.517^{\star \star}$ & $.425^{* *}$ & $.867^{\star \star}$ & $.735^{\star \star}$ & $.724^{\star *}$ & $.566^{* *}$ & $-.614^{* *}$ & $.790^{* *}$ & \\
\hline 12 & Working hours & $.163^{* *}$ & .024 & $-.664^{* *}$ & $-.624^{* *}$ & $-.875^{* *}$ & $-.828^{* *}$ & $-.818^{* *}$ & $-.681^{* *}$ & $.693^{* *}$ & $-.813^{* *}$ & $-.779^{*}$ \\
\hline
\end{tabular}


Figure 1

\section{Procedure of Invitation, recruitment and physical examination of the military personnel}

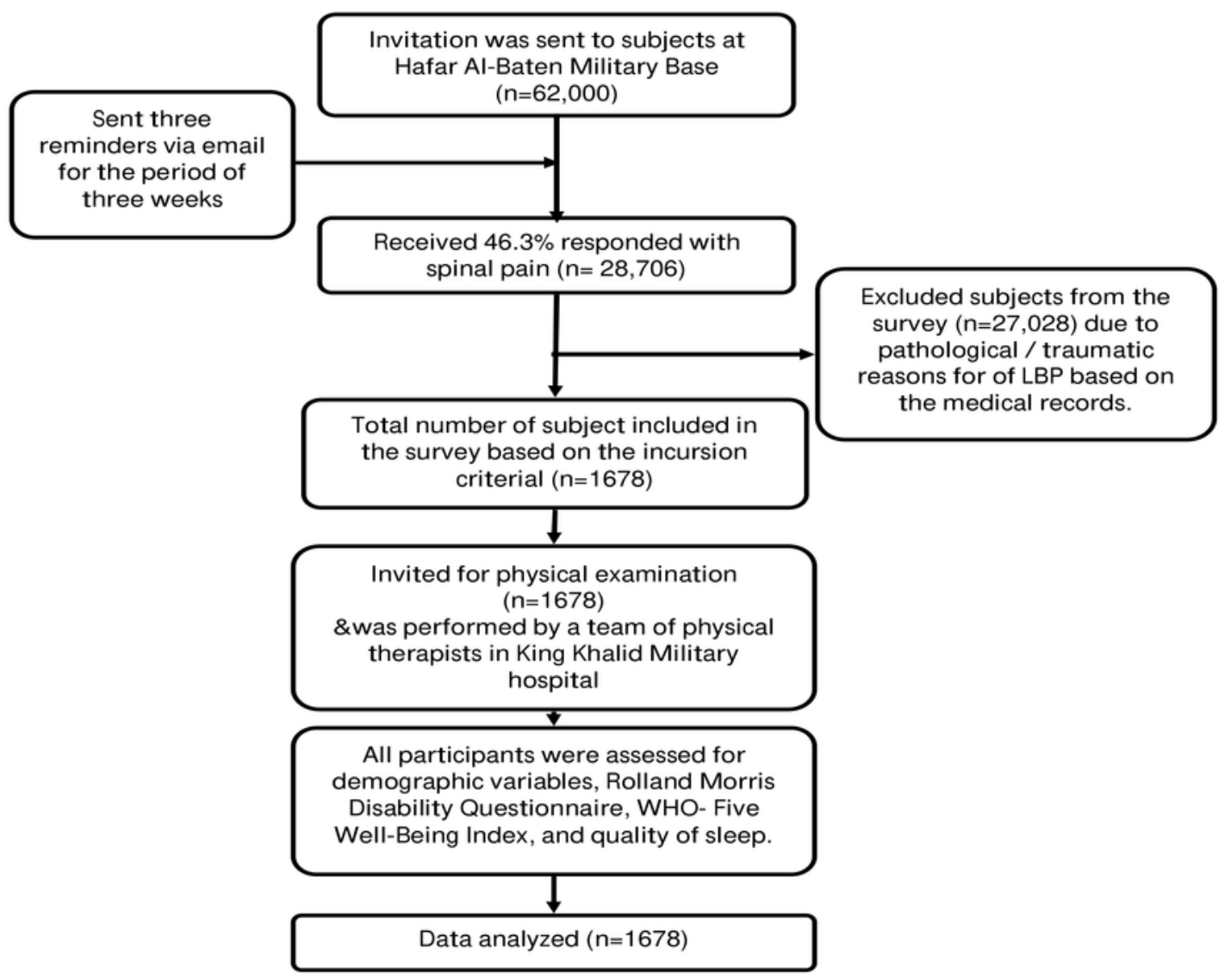


Figure 2

Flow Chart of the sample population, respondents, inclusion, and analysis.

* Percentage calculated for the participants who responded to have back pain, ** Percentage calculated from the sample population. 


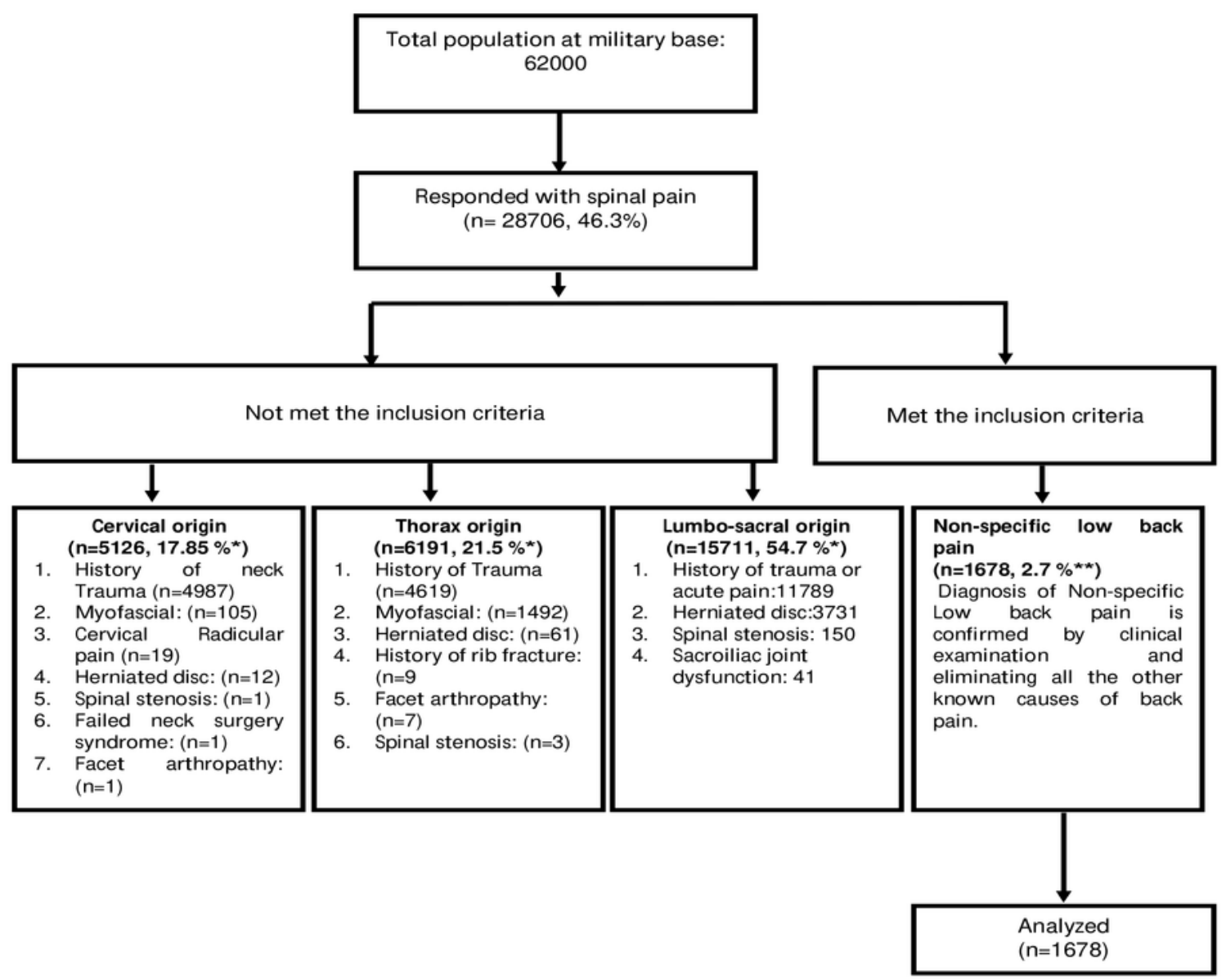

